\title{
Gender and Field of Study and Performance on an English Language Proficiency Test
}

\author{
Ebrahim Khodadady \\ Ferdowsi University of Mashhad, International Branch, Mashhad, Iran \\ Email: ekhodadady@gmail.com \\ Beheshteh Shakhsi Dastgahian \\ Ferdowsi University of Mashhad, International Branch, Mashhad, Iran
}

\begin{abstract}
This study reports the performance of five thousand one hundred and eighty three undergraduate and graduate students on a language proficiency test called Ministry of Science, Research and Technology (MSRT). It consists of one hundred traditional multiple choice items selected from the disclosed Test of English as a Foreign Language and measures the listening and reading comprehension abilities as well as structural knowledge. It was taken by students majoring in five branches of knowledge, i.e., agriculture, basic sciences, engineering, humanities and social sciences, and medical sciences, in Iran. The One-Way ANOVA analysis of scores showed that female test takers scored significantly higher than males not only on the MSRT but also on its structure, listening and reading comprehension subtests. The same analysis also showed that engineering test takers scored significantly higher than agriculture, basic sciences and humanities and social sciences on the listening comprehension subtest and MSRT. The scores of engineering and medical science test takers on the reading comprehension subtest were, however, significantly higher than humanities and social science test takers only. The results are discussed and suggestions are made for future research.
\end{abstract}

Index Terms - foreign language, proficiency, listening, reading, structure

\section{INTRODUCTION}

Language proficiency is treated as an ability which is measured "to determine whether this ... ability corresponds to specific language requirement" (Valette, 1977, p. 6). The Test of English as a Foreign Language (TOEFL) is, for example, designed by Educational Testing Service (ETS) in America as a traditional multiple choice item English language proficiency test. The scores obtained on the TOEFL "help the admissions staff determine if your skills are adequate for enrollment into the program of study you have selected" (ETS, 1995, p. 6).

The paper-and-pencil version of TOEFL consists of three separate subtests: 1) listening comprehension, 2) structure and written expression and 3) reading comprehension. The third subtest contains "a variety of short passages on academic subjects. Each passage is followed by question about the meaning of the passage" (ETS, 1991, p. 7). This subtest along with the other subtests of the TOEFL are designed by language testing specialists on the assumption that they provide a fair measure of adult English language proficiency for test takers whose first and/or second languages are not English.

Fairness of an ability measure such as the TOEFL is defined as providing test takers with scores which are not affected by extraneous variables such as cognitive styles, gender, field of study and educational level. Khodadady, Fatemi and Etminan (2012), for example, employed two tests to explore the relationship between the test takers' cognitive styles and their English language proficiency (ELP). They utilized the Group Embedded Figures Test (GEFT) designed by Witkin, Oltman, Raskin, and Karp (1971) and the schema-based cloze multiple choice item test (S-Test) designed by Gholami (2006) as measures of cognitive styles and ELP, respectively.

As language proficiency measures, S-Tests differ from the TOEFL in terms of their constituting passages and the nature of items developed on the words comprising the passages, i.e., schemata. S-Tests are designed on authentic passages which are written to be read by literate English speakers. In addition to authenticity, the alternatives comprising the items have syntactic, semantic and discoursal relationships not only with the keyed response but also with the schemata comprising the whole passage (e.g., Khodadady \& Elahi, 2011).

Khodadady, Fatemi and Etminan (2012) administered the S-Test to 253 undergraduate and graduate students of English and used their scores to divide them into low, middle, and high proficiency groups. The performance of these three groups on the GEFT revealed that "neither low nor high proficiency groups employed their cognitive styles because their performance on the two tests" showed no significant relationship. The middle proficiency group, however, utilized both field-dependent and field-independent styles "to compensate for their partially acquired language proficiency" (p. 806).

To the best knowledge of the present researchers, no independent study has, nonetheless, been conducted to explore the fairness of the TOEFL in a foreign language context such as Iran. To fill the gap, the present study attempts to find 
out whether the disclosed TOEFL administered by the Ministry of Science, Research, and Technology (MSRT) in Iran and named the MSRT produces significantly different scores for test takers having different gender and field of study. Such an attempt is educationally important because a large number of applicants take the MSRT every year and many decisions are made on the basis of their performance.

According to the Iran MSRT (2011a, 2011b, 2011c), the test is held in thirteen cities, i.e., Ahwaz, Babolsar, Esfahan, Hamedan, Kermanshah, Mashhad, Qom, Rasht, Shiraz, Tabriz, Tehran, Urmia, and Zahedan, monthly. In addition to being a requirement for getting admitted to graduate studies in Iranian universities, governmental scholarships are awarded only to those whose performances are above the cutoff score on the MSRT, i.e., 50 out of 100, for agriculture, engineering, and basic sciences, and 55 out of 100 for humanities and social sciences. Moslemy Naeeny (2011) announced that 13943, 17526, and 14757 applicants took the MSRT in the years 2009, 2010, and 2011, respectively.

\section{MEthodOLOGY}

\section{A. Participants}

The scores and some bio data of five thousand one hundred and eighty three applicants who took the MSRT on September $8^{\text {th }}$ and $18^{\text {th }}, 2011$ were given to the present researchers by an authority in the Iran MSRT. Since 703 test takers had scored lower than 11 out of 100 on the test, they were excluded from all statistical analyses. The remaining 4480 test takers had studied various fields as diverse as Arabic language, arts, law and physiology. These fields were classified into five major branches as shown in Table 1. As can be seen, the largest number of test takers had studied medical sciences $(\mathrm{n}=1349,30.1 \%)$.

TABLE 1.

THE MAJOR BRANCHES OF KNOWLEDGE STUDIED BY TEST TAKERS

\begin{tabular}{|l|l|l|l|l|}
\hline Branches & Frequency & Percent & Valid Percent & Cumulative Percent \\
\hline No specified & 15 & .3 & .3 & .3 \\
\hline Agriculture & 309 & 6.9 & 6.9 & 7.2 \\
\hline Basic Sciences & 1296 & 28.9 & 28.9 & 36.2 \\
\hline Engineering & 713 & 15.9 & 15.9 & 52.1 \\
\hline Humanities and Social Sciences & 798 & 17.8 & 17.8 & 69.9 \\
\hline Medical Sciences & 1349 & 30.1 & 30.1 & 100.0 \\
\hline Total & 4480 & 100.0 & 100.0 & \\
\hline
\end{tabular}

Out of 4480 test takers, $1942(43.4 \%)$ and $2538(56.6 \%)$ were female and male in gender, respectively. While 912 $(20.4 \%)$ did not specify what academic degree they held at the time of examination, 170 (3.8\%), 2992 (66.8\%) and 406 (9.1\%) had obtained their BA/BSc, MA /MD /MSc and $\mathrm{PhD}$ degrees from Iranian universities, respectively. No data were provided as regards the participants' age; however, they were all speaking Persian as their mother/second language.

\section{B. Instrument}

Based on the disclosed paper-and-pencil TOEFL items, a language proficiency test called MSRT is compiled in Iran. It consists of three subtests, i.e., listening comprehension, structure and written expressions and reading comprehension.

\section{Listening Comprehension}

The listening comprehension subtest of the MSRT consists of thirty traditional multiple choice items developed on short conversations between two speakers. Upon hearing the conversation, the test takers must read the four choices offered for the question raised, choose the correct alternative and mark it on the answer sheet as the example below illustrates. (The time allotted is 15 minutes.)

$\begin{array}{ll} & \text { On the recording you hear: } \\ & \text { (Woman): I don't like this painting very much. } \\ \text { Example: } & \text { (Man): Neither do I. } \\ & \text { (Narrator): What does the man mean? } \\ \text { Alternatives } & \text { A He doesn't like the painting either }\end{array}$

C He doesn't know how to paint
D He doesn't know what to do.

\section{Structure and Written Expressions}

The structure and written expressions subtest of the MSRT consists of thirty multiple choice items. The items dealing with the structure present a sentence in which a word or phrase is deleted and offered along with three alternatives to measure test takers structural knowledge as shown in sample item below. (The time allotted is 20 minutes.)

Example:

Alternatives ... no conclusive eviden
the rest of the world.

A Even

B Although
C But

D So 
Four parts of a sentence are, however, underlined for written expression items and the test takers are required to choose the part which violates a structural rule of the English language as shown in the example below. (The time allotted is 20 minutes.)

Example:

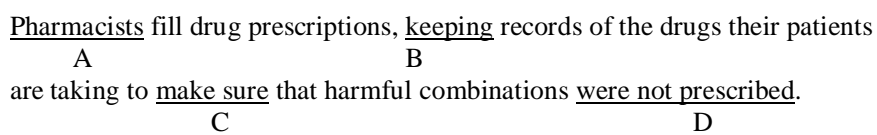

\section{Reading Comprehension}

Forty multiple choice items developed on several short passages constitute the reading comprehension section of the MSRT. All the lines of the passage are numbered for the ease of reference and the meaning of some words appearing in certain lines are questioned as shown in the example below.

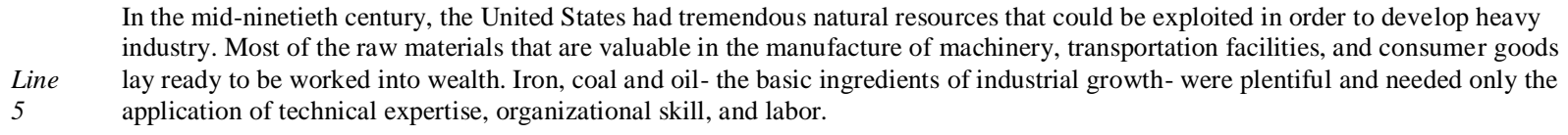
industry. Most of the raw materials that are valuable in the manufacture of machinery, transportation facilities, and consumer goods

Example:

The word "only" in line 5 is closest in meaning to

Alternatives

A merely

C greatly

D rapidly

In addition to the meaning of the words constituting the reading passages, most items require test takers to read them carefully and based on the information given in the texts select the alternative which they think offers the best answer to each question as shown in the item below. (The time allotted is 40 minutes.)

Example: What does the passage mainly discuss?

A. The history of railroads in the United States

Alternatives

B. The major United Stated industrial centers

C. Factors that affected industrialization in the United States

D. The role of agriculture in the nineteenth century

\section{Procedure}

The Iran MSRT holds the test under standard conditions several times in several cities during the year. According to authorities 13943, 17526, and 14757 applicants to higher education took the MSRT in 2009, 2010, and 2011, respectively. The participants of this study took the test in September 2011 and their scores were given to the researchers in July 2012.

\section{Data Analysis}

Since there was no data available as regards the test takers' performance on individual items, the scores on the listening comprehension, structure and written expression as well as the MSRT itself were subjected to KR-21 formula to estimate their level of reliability. The estimate is based on the assumption that "all items are of the same difficulty" (Thorndike, 2005, p. 119). The One-Way ANOVA test was employed to find out whether female and male test takers' mean scores on the test and subtests would differ significantly from each other. It was also utilized to explore whether test takers majoring in different branches of knowledge would perform differently on the test. The descriptive as well as inferential statistics were estimated via IBM SPSS Statistics 19.00 in order to test the five null hypotheses below:

H1: There will be no significant difference in the mean scores obtained by female and male participants on the MSRT and its three subtests.

H2: There will be no significant difference in the mean scores of test takers studying agriculture, basic sciences, engineering, humanities and social sciences, and medical sciences on the listening comprehension subtest of the MSRT.

H3: There will be no significant difference in the mean scores of test takers studying agriculture, basic sciences, engineering, humanities and social sciences, and medical sciences on the structure subtest of the MSRT.

H4: There will be no significant difference in the mean scores of test takers studying agriculture, basic sciences, engineering, humanities and social sciences, and medical sciences on the reading comprehension subtest of the MSRT.

H5: There will be no significant difference in the mean scores of test takers studying agriculture, basic sciences, engineering, humanities and social sciences, and medical sciences on the MSRT.

\section{RESULTS AND DISCUSSION}

Table 2 presents the descriptive statistics as well as KR21 reliability coefficient of the MSRT and its subtests. As can be seen, the MSRT enjoys an acceptable level of reliability, i.e., .78. Among the three subtests, the reading comprehension has the highest standard deviation, i.e., 4.70, indicating that, it could differentiate among the test takers best. The reliability of the reading comprehension subtest, i.e., .58, is; however, relatively lower than that of listening comprehension subtest, i.e., .60, while the structure subtest is the lowest, i.e., .54. 
TABLE 2

DESCRIPTIVE STATISTICS AND RELIABILITY ESTIMATE OF THE MSRT AND ITS SUBTESTS (N = 4480)

\begin{tabular}{|l|l|l|l|l|l|l|l|}
\hline Tests & \# of items & Mean & Variance & SD & Skewness & Kurtosis & KR-21 \\
\hline Listening & 30 & 9.56 & 15.370 & 3.920 & 1.212 & 2.081 \\
\hline Grammar & 30 & 13.71 & 17.641 & 4.200 & .266 & .60 \\
\hline Reading & 40 & 17.33 & 22.053 & 4.696 & .222 & .020 & .106 \\
\hline MSRT & 100 & 40.60 & 104.761 & 10.235 & .773 & .54 & 1.104 \\
\hline
\end{tabular}

Table 3 presents the descriptive statistics related to female and male test takers' performance on the MSRT and its subtests. As can be seen, the female test takers have outperformed their male counterparts. The One-Way ANOVA analysis showed that the mean scores of female test takers not only on the listening comprehension $(\mathrm{F}=16.851, \mathrm{df}=1$, $p<.001)$, structure $(\mathrm{F}=52.365, \mathrm{df}=1, p<.001)$, and reading comprehension $(\mathrm{F}=12.143, \mathrm{df}=1, p<.001)$ subtests but also on the MSRT $(\mathrm{F}=37.654, \mathrm{df}=1, p<.001)$ are significantly higher than those of male test takers. These results thus disconfirm the first hypothesis that there will be no significant difference in the mean scores obtained by female and male participants on the MSRT and its three subtests.

TABLE 3.

DESCRIPTIVE STATISTICS OF FEMALE AND MAKE TEST TAKERS

\begin{tabular}{|l|l|l|l|l|l|}
\hline Tests and subtests & Gender & N & Mean & SD & Std. Error \\
\hline \multirow{2}{*}{ Listening Comprehension } & Female & 1942 & 9.84 & 4.059 & .092 \\
\cline { 2 - 6 } & Male & 2538 & 9.36 & 3.798 & .075 \\
\hline \multirow{2}{*}{ Structure } & Female & 1942 & 14.23 & 4.128 & .094 \\
\cline { 2 - 6 } & Male & 2538 & 13.31 & 4.213 & .084 \\
\hline \multirow{2}{*}{ Reading Comprehension } & Female & 1942 & 17.61 & 4.594 & .104 \\
\hline \multirow{2}{*}{ MSRT } & Male & 2538 & 17.11 & 4.763 & .095 \\
\hline & Female & 1942 & 41.67 & 10.311 & .234 \\
\cline { 2 - 6 } & Male & 2538 & 39.78 & 10.103 & .201 \\
\hline
\end{tabular}

Table 4 presents the descriptive statistics of scores obtained on the listening comprehension subtest by the test takers majoring in five major branches of knowledge. The One-Way ANOVA analysis showed that the mean scores of five branches differ significantly from each other $(\mathrm{F}=9.038, \mathrm{df}=4, p<.001)$. Scheffe post hoc test, however, revealed that only two majors outperformed others significantly.

TABLE 4.

DESCRIPTIVE STATISTICS OF SCORES ON LISTENING COMPREHENSION SUBTEST

\begin{tabular}{|l|l|l|l|l|}
\hline Five Branches of Knowledge & N & Mean & SD & Std. Error \\
\hline Agriculture & 309 & 9.21 & 4.002 & .228 \\
\hline Basic Sciences & 1296 & 9.38 & 3.827 & .106 \\
\hline Engineering & 713 & $\mathbf{1 0 . 2 3}$ & 3.989 & .149 \\
\hline Humanities and Social Sciences & 798 & 9.17 & 3.881 & .137 \\
\hline Medical Sciences & 1349 & $\mathbf{9 . 7 3}$ & 3.943 & .107 \\
\hline Total & 4465 & 9.57 & 3.924 & .059 \\
\hline
\end{tabular}

Table 5 presents the Scheffe post hoc test of the mean scores obtained by test takers majoring in five branches on the listening comprehension subtest of the MSRT. (The table is simplified and shortened to save space.) As can be seen, only the engineering test takers have scored significantly higher than those majoring in agriculture, basic sciences and humanities and social sciences. The mean score of medical science test takers is also significantly higher than that of humanities and social sciences only. These results partially disconfirm the second hypothesis that there will be no significant difference in the mean scores of test takers studying agriculture, basic sciences, engineering, humanities and social sciences, and medical sciences on the listening comprehension subtest of the MSRT.

TABLE 5.

SCHEFFE POST HOC TEST OF SCORES ON LISTENING COMPREHENSION SUBTEST

\begin{tabular}{|c|c|c|c|c|}
\hline (I) Branch & (J) Branch & Mean Difference (I-J) & Std. Error & Sig. \\
\hline \multirow{4}{*}{ Engineering } & Agriculture & $1.015^{*}$ & .266 & .006 \\
\hline & Basic Sciences & $.847^{*}$ & .182 & .000 \\
\hline & Humanities and Social Sciences & $1.054^{*}$ & .202 & .000 \\
\hline & Medical Sciences & .502 & .181 & .104 \\
\hline \multirow{4}{*}{ Medical Sciences } & Agriculture & .513 & .247 & .364 \\
\hline & Basic Sciences & .345 & .152 & .272 \\
\hline & Engineering & -.502 & .181 & .104 \\
\hline & Humanities and Social Sciences & $.552^{*}$ & .175 & .041 \\
\hline
\end{tabular}


Table 6 presents the descriptive statistics of mean scores obtained on the structure subtest taken by the test takers majoring in five major branches of knowledge. The One-Way ANOVA analysis showed that the mean scores of the five branches differ significantly from each other $(\mathrm{F}=13.536, \mathrm{df}=4, p<.001)$.

TABLE 6.

DESCRIPTIVE STATISTICS OF SCORES ON STRUCTURE SUBTEST

\begin{tabular}{|l|l|l|l|l|}
\hline Five Branches of Knowledge & N & Mean & SD & Std. Error \\
\hline Agriculture & 309 & 13.52 & 4.204 & .239 \\
\hline Basic Sciences & 1296 & 13.87 & 3.889 & .108 \\
\hline Engineering & 713 & 14.41 & 4.411 & .165 \\
\hline Humanities and Social Sciences & 798 & 12.88 & 4.565 & .162 \\
\hline Medical Sciences & 1349 & 13.74 & 4.058 & .110 \\
\hline Total & 4465 & 13.72 & 4.197 & .063 \\
\hline
\end{tabular}

Table 7 presents the Scheffe post hoc test of the mean scores obtained by test takers on the structure subtest of the MSRT. As can be seen, the basic science, engineering and medical science test takers have scored significantly higher than those majoring in humanities and social sciences. The mean score of engineering test takers is also significantly higher than those of agriculture and medical sciences as well. These results disconfirm the third hypothesis that there will be no significant difference in the mean scores of test takers studying agriculture, basic sciences, engineering, humanities and social sciences, and medical sciences on the structure subtest of the MSRT to a large extent.

TABLE 7

SCHEFFE POST HOC TEST OF STRUCTURE

\begin{tabular}{|c|c|c|c|c|}
\hline (I) Branch & (J) Branch & Mean Difference (I-J) & Std. Error & Sig. \\
\hline \multirow{4}{*}{ Basic Sciences } & Agriculture & .353 & .264 & .775 \\
\hline & Engineering & -.541 & .195 & .102 \\
\hline & Humanities and Social Sciences & $.988^{*}$ & .188 & .000 \\
\hline & Medical Sciences & .127 & .162 & .962 \\
\hline \multirow{4}{*}{ Engineering } & Agriculture & $.895^{*}$ & .284 & .042 \\
\hline & Basic Sciences & .541 & .195 & .102 \\
\hline & Humanities and Social Sciences & $1.529^{*}$ & .215 & .000 \\
\hline & Medical Sciences & $.668^{*}$ & .193 & .018 \\
\hline \multirow{4}{*}{ Medical Sciences } & Agriculture & .226 & .263 & .946 \\
\hline & Basic Sciences & -.127 & .162 & .962 \\
\hline & Engineering & $-.668^{*}$ & .193 & .018 \\
\hline & Humanities and Social Sciences & $.861^{*}$ & .186 & .000 \\
\hline
\end{tabular}

* The mean difference is significant at the 0.05 level

Table 8 presents the descriptive statistics of mean scores obtained on the reading comprehension subtest taken by the test takers majoring in five branches of knowledge. The One-Way ANOVA analysis showed that the mean scores of five branches differ significantly from each other $(\mathrm{F}=5.551, \mathrm{df}=4, p<.001)$.

TABLE 8

DESCRIPTIVE STATISTICS OF READING COMPREHENSION SUBTEST

\begin{tabular}{|l|l|l|l|l|}
\hline Five Branches of Knowledge & N & Mean & SD & Std. Error \\
\hline Agriculture & 309 & 16.85 & 4.618 & .263 \\
\hline Basic Sciences & 1296 & 17.38 & 4.492 & .125 \\
\hline Engineering & 713 & 17.63 & 4.938 & .185 \\
\hline Humanities and Social Sciences & 798 & 16.75 & 5.090 & .180 \\
\hline Medical Sciences & 1349 & 17.58 & 4.498 & .122 \\
\hline Total & 4465 & 17.33 & 4.697 & .070 \\
\hline
\end{tabular}

Table 9 presents the Scheffe post hoc test of the mean scores on the reading comprehension subtest of MSRT. As can be seen, only the mean scores of engineering and medical science students are significantly higher than that of humanities and social sciences. These results partially disconfirm the fourth hypothesis that there will be no significant difference in the mean scores of test takers studying agriculture, basic sciences, engineering, humanities and social sciences, and medical sciences on the reading comprehension subtest of the MSRT.

TABLE 9

SCHEFFE POST HOC TEST OF READING COMPREHENSION

\begin{tabular}{|l|l|l|l|l|}
\hline (I) Branch & (J) Branch & Mean Difference (I-J) & Std. Error & Sig. \\
\hline \multirow{4}{*}{$\begin{array}{l}\text { Humanities and Social } \\
\text { Sciences }\end{array}$} & Agriculture & -.097 & .314 \\
\cline { 2 - 5 } & Basic Sciences & -.629 & .211 \\
\cline { 2 - 5 } & Engineering & $-.878^{*}$ & .242 & .099 \\
\cline { 2 - 5 } & Medical Sciences & $-.825^{*}$ & .209 & .010 \\
\hline
\end{tabular}

* The mean difference is significant at the 0.05 level 
Table 10 presents the descriptive statistics of mean scores obtained on the MSRT taken by the test takers majoring in five major branches of knowledge. The One-Way ANOVA analysis showed that the mean scores of five majors differ significantly from each other $(\mathrm{F}=12.404, \mathrm{df}=4, p<.001)$.

TABLE 10.

DESCRIPTIVE STATISTICS OF MSRT

\begin{tabular}{|l|l|l|l|l|}
\hline Five Branches of Knowledge & N & Mean & SD & Std. Error \\
\hline Agriculture & 309 & 39.58 & 10.158 & .578 \\
\hline Basic Sciences & 1296 & 40.64 & 9.479 & .263 \\
\hline Engineering & 713 & 42.27 & 10.796 & .404 \\
\hline Humanities and Social Sciences & 798 & 38.81 & 11.004 & .390 \\
\hline Medical Sciences & 1349 & 41.05 & 10.008 & .272 \\
\hline Total & 4465 & 40.62 & 10.237 & .153 \\
\hline
\end{tabular}

Figure 1 presents the plot drawn on the mean scores obtained on the MSRT. As can be seen, the engineering and medical science test takes' mean score is the first and second highest. The humanities and social sciences as well as agriculture test takers have scored the first and second lowest, respectively.

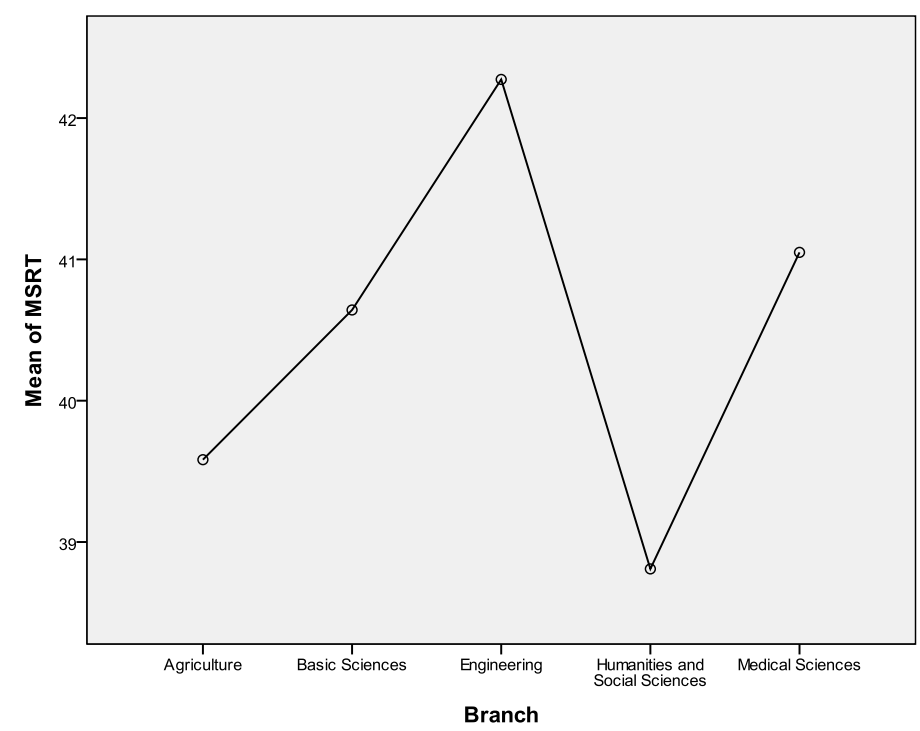

Figure 1. Means plots

Table 11 presents the Scheffe post hoc test of the mean scores on the MSRT. As can be seen, the mean scores of basic science, engineering and medical science students are significantly higher than that of humanities and social sciences. The scores of engineering students are also significantly higher than those of agriculture and basic sciences. These results thus disconfirm the fifth hypothesis that there will be no significant difference in the mean scores of test takers studying agriculture, basic sciences, engineering, humanities and social sciences, and medical sciences on the MSRT.

TABLE 11.

SCHEFFE POST HOC TEST OF MSRT

\begin{tabular}{|c|c|c|c|c|}
\hline (I) Branch & (J) Branch & Mean Difference (I-J) & Std. Error & Sig. \\
\hline \multirow{3}{*}{ Basic Sciences } & Agriculture & 1.059 & .645 & .609 \\
\hline & Engineering & $-1.632^{*}$ & .475 & .019 \\
\hline & Medical Sciences & -.408 & .396 & .901 \\
\hline \multirow{2}{*}{ Engineering } & Agriculture & $2.691^{*}$ & .694 & .005 \\
\hline & Basic Sciences & $1.632^{*}$ & .475 & .019 \\
\hline \multirow{4}{*}{ Medical Sciences } & Agriculture & 1.467 & .642 & .266 \\
\hline & Basic Sciences & .408 & .396 & .901 \\
\hline & Engineering & -1.224 & .472 & .151 \\
\hline & Humanities and Social Sciences & $2.240^{*}$ & .455 & .000 \\
\hline
\end{tabular}

The results of this study are in line with those found by Clapham (1996), Moy (1975) and Shoham, Peretz, and Vorhau (1987). These researchers hypothesized that test takers would score significantly higher on the proficiency tests whose reading passages are closely related to their field of study. Although their findings did not confirm the hypothesis 
as regards all the fields investigated, Shoham et al. (1987) observed that "humanities and social science students did not do significantly better on the test passage that was considered to be more closely related to their academic discipline" (p. 86). Similarly, the humanities and social sciences students in this study had the lowest score on the MSRT and its subtests.

The findings of the present research, however, differ from Shoham et al. (1987) in that the passages comprising the reading comprehension subtest of the MSRT are not field specific. They usually deal with general topics and are mostly written or modified by testing specialists and thus lack authenticity (Khodadady, 1997, 1999). The very unauthentic nature of these passages, i.e., their being written for the sake of testing reading comprehension ability rather than being read for purposes other than testing, might have endowed these passages with certain features which are easily discerned by engineering and medical science test takers.

\section{CONCLUSION}

This study explored the performance of one thousand nine hundred and forty two female and two thousand five hundred and thirty eight male test takers on the MSRT proficiency test developed on the disclosed structure, listening and reading comprehension items taken from the disclosed TOEFL. Its findings showed that female test takers scored significantly higher than their male counterparts, implying that either female test takers' English proficiency is significantly higher than males or the MSRT is gender specific and its fairness is open to question.

The significantly different performance of test takers majoring in agriculture, basic sciences, engineering, humanities and social sciences, and medical sciences on the MSRT, however, seem to support its gender specificity because it is also affected by the test takers' field of study. Engineering test takers, for example, outperformed agriculture, basic sciences and humanities and social sciences on the listening comprehension subtest of MSRT. Their scores on the reading comprehension subtest were also significantly higher than humanities and social sciences. These results indicate that engineering test takers may have an attribute other than English proficiency which helps them perform better than agriculture and basic science test takers on some measures such as listening comprehension tests.

The non-language attribute possessed by engineering students seems to be shared partly by medical science test takers whose performance on the MSRT does not significantly differ from that of engineering. Similar to engineering, medical science test takers' scores on the reading comprehension subtest of the MSRT differ significantly from only humanities and social sciences. However, they do not score significantly higher than agriculture and basic sciences on the listening comprehension subtest as engineering test takers do. These results seem to support gender as well as major specificity of MSRT and call for the administration of other proficiency measures such as conventional C-Tests (KleinBraley, 1997), authentic C-Tests (Khodadady \& Hashemi, 2011) and S-Tests (Khodadady, 2012; Khodadady, Alavi, Pishghadam, \& Khaghaninezhad, 2012) along with the MSRT to replicate the study and secure fairness in testing in the light of future findings.

\section{ACKNOWLEDGEMENT}

The authors wish to thank the authorities of the Iran Ministry of Science, Research and Technology in general and Dr. Moslemy Naeeny in particular for providing them with the data analysed and discussed in this study.

\section{REFERENCES}

[1] Clapham, C. (1996). The development of IELTS: A study of the effect of background knowledge on reading comprehension. Cambridge: Cambridge University Press.

[2] Educational Testing Service. (1991). Reading for TOEFL: Workbook (2 $2^{\text {nd }}$ ed.). Princeton, NJ: ETS.

[3] Educational Testing Service. (1995). TOEFL test preparation kit: Workbook. Princeton, NJ: ETS.

[4] Gholami, M. (2006). The effect of content schema type on Iranian test takers' performance. Unpublished MA thesis, Ferdowsi University of Mashhad, Iran.

[5] Iran Ministry of Science, research, and technology. (2011a). The Address of MSRT holding place in Tehran and Other Cities. Retrieved July 26, 2012, from Ministry of science, Research and Technology Online Access: http://msrt-exam.msrt.ir.

[6] Iran Ministry of Science, research, and technology. (2011b). MSRT Information. Retrieved July 20, 2012, from Ministry of science, Research and Technology Online Access: http://msrt-exam.msrt.ir/loginpage.rose.

[7] Iran Ministry of Science, research, and technology. (2011c). New Instructions for overseas applicants' scholarships. Retrieved July 26, 2012, from Ministry of science, Research and Technology Online Access: http://www.msrt.ir/SitePages/NewsDetails.aspx?NewsID=274.

[8] Khodadady, E. (1997). Schemata theory and multiple choice item tests measuring reading comprehension. Unpublished PhD thesis, the University of Western Australia.

[9] Khodadady, E. (1999). Multiple-choice items in testing: Practice and theory. Tehran: Rahnama.

[10] Khodadady, E. (2012). Validity and tests developed on reduced redundancy, language components and schema theory. Theory and Practice in Language Studies, 2(3), 585-595.

[11] Khodadady, E., \& Elahi, M. (2012). The effect of schema-vs-translation-based instruction on Persian medical students' learning of general English. English Language Teaching, 5 (1), 146-165. URL: http://dx.doi.org/10.5539/elt.v5n1p146 (accessed 28/6/2010). 
[12] Khodadady, E., \& Hashemi, M. (2011). Validity and C-Tests: The role of text authenticity. Iranian Journal of Language Testing, 1(1), 30-41.

[13] Khodadady, E., Alavi, S. M., Pishghadam, R., \& Khaghaninezhad, M. S. (2012). Teaching general English in academic context: Schema-based or translation-based approach? International Journal of Linguistics, 4(1), 56-89. URL: http://dx.doi.org/10.5296/ijl.v4i1.1213 (accessed 12/8/2010).

[14] Khodadady, E., Fatemi, A. H., \& Etminan, S. (2012). Cognitive styles and performance on schema-based cloze multiple choice item tests: A fairness issue. Journal of Language Teaching and Research, 3(4), 806-813. doi:10.4304/j1tr.3.4.806-813.

[15] Klein-Braley, C. (1997). C-Tests in the context of reduced redundancy testing: an appraisal. Language Testing, 14(1), 47-84.

[16] Moslemi Naeeni, H. (2011). The Statistical tables of the MSRT Participants, Ministry of Science, Research and Technology. Mehr News Agency. Retrieved July 26, 2012, from http://www.mehrnews.com/fa/newsdetail.aspx?NewsID=1451914.

[17] Moy, R. H. (1975). The effect of vocabulary clues, content familiarity and English proficiency on cloze scores. Unpublished M. A. thesis, UCLA.

[18] Shoham, M., Peretz, A. S., \& Vorhau, R. (1987). Reading comprehension tests: General or subject specific? System, 15, 81-8.

[19] Thorndike, R. M. (2005). Measurement and Evaluation in Psychology and Education (7th ed.). Upper Saddle River, NJ: Pearson Education.

[20] Vallete, R. M. (1977). Modern language testing ( $2^{\text {nd }}$ ed.). New York: Harcourt Jovanovich Brace.

[21] Witkin, H.A., Oltman, P.K., Raskin, E., \& Karp, S.A. (1971). A Manual for the Group Embedded Figures Test. Palo Alto, CA: Consulting Psychologists Press.

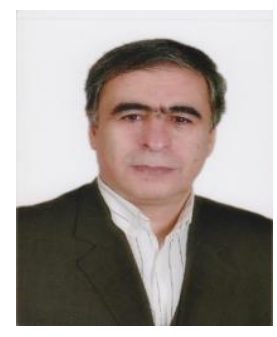

Teaching.

Dr. Khodadady is currently a member of Teaching English Language and Literature Society of Iran (TELLSI), TESL Ontario and European Society for Translation Studies. He is on the editorial board of Ferdowsi Review: An Iranian Journal of TESL, Literature and Translation Studies and has reviewed some research papers for Iranian Journal of Applied Linguistics and TESL Canada Journal as a guest reviewer.

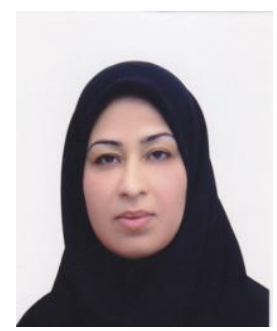

Beheshteh Shakhsi Dastgahian was born in Iran in 1973. She is the MA student in Applied Linguistics in Ferdowsi University of Mashhad, International Branch, Mashhad, Iran. She is currently teaching English as foreign language to high school and pre-university students in the educational district three in Mashhad, Iran. She has participated in all educational programs related to the State Department of Education up to now, and hold a Diploma in Computer Skills. Her main research interests include Language Proficiency and Multiple Intelligences. 